\title{
The Research on Rural Dispute and Its Diversity Settlement Mechanism
}

\author{
Tao Tao \\ Lecturer of The Law School of Beihua University, Jilin,Jilin Province,China
}

Keywords: The rural disputes, Basic level rule of law, Dispute resolution mechanism Diversification.

\begin{abstract}
Now the disputes between rural society have been mixed and diversified, and the conflict resolution mechanism has a tendency to diversify. How to build a multi-functional, procedural, litigable, diverse dispute resolution system, to solve a particular rural dispute ultimately has to be an important project to build the legal countryside.
\end{abstract}

\section{Introduction}

As an integral part of national governance modernization and legalization, the modernization and legalization of rural social governance should be given full attention. Among them, the effective solution of rural disputes is the most practical goal and effect of modernization of rural social governance and the rule of law. With the impact of social development on the rural areas, farmers and rural areas as the subject of disputes have undergone significant changes including values, social cognition, rights awareness and behavior patterns, which have brought out the characteristics of diversified interests, complicated disputes, and even the mass of disputes. The most typical rural disputes arising from the transfer of land use rights, environmental pollution, and village affairs management are in fact the contradiction between the direct or indirect adjustment of personal interests and national interests, the interests of local governments and the interests of the central government, the public interests and the commercial interests. In the context of the dispute, it shows that history and reality, the laws of the country and the local law and the individual and the individual desires the differences, the differences between the individual and the individual, and the differences between the individual and the group. Because of the new interest demands brought by the economic development, the rural dispute has broken through the traditional disputes between neighbors and family disputes, forming a new pattern of rural disputes based on land disputes and environmental disputes. The subject of disputes is based on unity or the common interest demands, and the disputes scale together, and even become a mass event frequently. These temporal changes are the reason that to explore the mechanisms of rural dispute resolution, and to diversificate the rural dispute resolution system. Dispute resolution mechanism is a complete system that a specific organization (group) can be determined based on system, rules and follow the procedures required to solve the dispute of .Diversified dispute settlement mechanism is intended to dispute settlement mechanism of the four elements (agency (organization), the systems, rules, procedures) on diversification, usually divided into legal and non-legal dispute resolution mechanism dispute settlement mechanism. In view of the litigation mechanism of statutory, and the domain we discuss which the traditional still play a role of rural culture, so this article will mainly discuss the construction of the non-litigation dispute resolution mechanism

\section{The Dilemma of Rural Dispute Settlement Mechanism}

1. The legislative deficiencies of the people's mediation act have caused the difficulties in practice, and it affects the resolution of non-litigation disputes. The concrete content of the law of people's mediation is not clear and detailed, which is not conducive to practical operation. For 
example, although article 9 of the people's mediation act stipulates that the members of the people's mediation committee shall be elected by the villagers' meeting or the village representative meeting or the residents' meeting. However, due to the fact that the villagers' meetings and the villagers' representative meetings tend to be in the form, the establishment of the people's mediation committee has basically stayed on the paper, and the composition of the people's mediation committee in many places is basically consistent with the members of the village committee, even the two brands of a set of people, leading to the fact that the village committee is still doing mediation work in real life. In this situation, the subject of the dispute often abandons the mode of people's mediation in favor of a petition or lawsuit as a dispute resolution, which seriously affects the effectiveness of the mediation of the people as a non-litigation dispute resolution mechanism.

2. The inherent characteristics of litigation mechanism limit its role as the settlement mechanism of rural dispute. We know that the public relief method has an outstanding cost problem compared to the private relief, that is, the public relief often requires the support of objective conditions such as system, mechanism, hardware configuration, and professional staffing. Litigation is the most typical form of public welfare to be dependent on the objective conditions, and the hard requirement for objective conditions is not just to be achieved in rural areas today. Procedural justice, highly specialized, clear rules, "based on facts and the law as the criterion" are the advantages of the litigation mechanism, but in the face of rural disputes, it shows more the contradictions between the legal rules and the social norms of tradition, morality, customs and rationality. The contradiction of procedural justice and entity justice; the contradiction between the real and the objective reality; contradictions of fairness and efficiency; the contradiction between high specialization and common sense requirements of the parties involved in programming design; the uncertainty of the rules and the inflexibility of procedures and the need for flexibility in solving special cases; the relationship between the simple rights and obligations involved and the complex social relations behind the dispute, etc. ${ }^{[1]}$, the conflict between the conflict resolution and the dispute itself, has caused the original rural dispute to be resolved, but it has increased the "new dispute" between purpose and means. It can be proved that litigation means is not the preferred method of rural dispute settlement.

3.To face up to the current development and change in rural areas is the basis for solving rural problems. Some people describe the change of rural migrant workers in recent years from the migrant workers carrying the luggage rolls to the rural migrant workers carrying the boxes. The large number of urban private business owners reflect that the current migrant workers are no longer as conservative as in the past. The subject consciousness and the awareness of rights have been significantly enhanced, and job-hopping has become an extremely common behavior. Now, when the subject of the rural dispute is choosing dispute resolution, there is a large number of rational factors and irrational factors. You can't exaggerate the status and extent of the law and regulations in rural disputes when you see the progress of the rural rule of law; it's more important to focus on the ongoing and escalating violence and illegal behavior.

\section{Reconstruction of Rural Diversification Dispute Settlement Mechanism}

It is a core principle to deal with rural disputes and to practice the development of the rule of law in rural areas. To improve the legal literacy of the rural people, it is no doubt that it is a strong guarantee to resolve rural disputes and not even produce dissension. The most effective publicity is the personal experience of the subject of the dispute, which has a vital role in improving legal awareness and the confidence of the law. The improvement of legal consciousness and legal literacy, the combination of law and law in dispute resolution, realizing the integration of value level, social order level and the subject psychology and behavior of dissension, must rely on institutional guarantee.

First, we should establish the concept of diversity of dispute settlement mechanism. It can be said that the general promotion of the consciousness of the people's rights from the theory to practice is the greatest achievement of the rule of law in our country. The problem with that is that there is a conflict between human rights awareness and the lack of legal knowledge. In the emergence of the dispute, the most important and urgent focus of the dispute is not the legal 
stipulation or the way of action, but the timely and effective guarantee of the self-cognition of the subject of the dispute. The logic of this conflict is more serious in the countryside, the rural disputes compared to city dispute subject, more care about through the way of low cost, high efficiency, makes the dispute is in fact the solution. Solution actual problem oriented logic, means that you need to provide a variety of dispute solution for the disputes in the specific dispute the main body independent choice, means a kind of multiple dispute resolution mechanism, "the concept of diversified dispute settlement mechanism that litigation and non-litigation, legal mechanism and other social adjustment mechanism, the state power and social autonomy, public relief and social relief and private relief force coordination between interaction, so as to realize the function and value diversity." ${ }^{[2]}$ According to the current situation of rural disputes and the reality of social development, we should emphasize the concept of diversity of dispute resolution mechanisms, not only to continue to change the old habits of the litigious and stigmatism, but also to abandon the "litigant omnipotence", which should be based on the non-litigation dispute settlement mechanism, the lawsuit as the auxiliary, and convey the idea of litigation as the last solution to the dispute. Second, we need to improve relevant legislation and enforce laws. Security law, property law, forest law, the land contract law and other relevant laws about land circulation, such as compensation system is directly related to the specific provisions of the interests of farmers there are many loopholes and extensive regulation, poor operability in practice, some even have negative effect is intensified disputes; the administrative permit law, the act of the people's conciliation, the complaint reporting regulations and other laws and regulations and the demolition ordinance, etc. According to the individual local government rules, there is also a serious impact on farmers' vital interests. These are the dispute reasons on the level of the system of rules, an urgent need to the legislature and deal with the relevant government functional departments.

Second, it is necessary to strengthen the implementation of relevant laws and regulations, and "the act is not enough to do it" . The legal standard of text is only to be put into practice, to really show its value.

Third, we should grasp the role of government and regulate administrative behavior. Rural relations of the dispute in rural areas, the rule of law is the needs of the construction of harmonious rural guiding type, a service-oriented, responsible government. "Modern rural development, relying on the necessity of real is the construction of grassroots regime." ${ }^{[3]}$ In the process, the government should not be the "night watchman" government, and should change to the positive guidance, service type and responsible government, and should build a reasonable institutional carrier under the framework of the rule of law, and then improve the rural self-government under the guidance of the government. It is an important part of the construction of grass-roots government to govern the dispute resolution ability of "autonomous guidance, behavior guidance, right relief, communication and coordination". Governments at all levels, especially those directly oriented to the grass-roots level, must regulate their own administrative actions and conduct their administration according to law.

Fourth, establish a rural arbitration institution. The arbitration procedure is simple, flexible and efficient, which perfectly matches the simple, flexible and efficient demands of the rural areas. And because the arbitration is based on the voluntariness of the litigants, the antagonism between the subjects of the dispute has also been alleviated, which reduces the inconsistency and the sharp nature, and has a more positive effect on improving the interpersonal relationship and the reconstruction of the harmonious order. Through the legislation, the creditor's rights disputes, labor disputes, consumption disputes, medical disputes, environmental pollution and so on are included in the arbitration scope, and the status and efficiency of arbitration in rural disputes are strengthened. To increase the publicity of the arbitration system, through various forms to publicize and promote the arbitration, let farmers understand the advantages of arbitration and increase the way to resolve rural disputes.

Fifth, improve the rural legal aid system. Improving the rural legal aid system not only helps the rural residents to resolve the specific disputes in cases, but also promotes the legal consciousness and legal literacy of the rural people and reduces the irrational elements that appear in dispute 
resolution. Let the rural people can study law, use law,solve the current farmers in the process of dispute resolution to maintain their own rights and interests. It will effectively resolve dispute resolution and irrational factors exist in the process of safeguarding rights, let the dispute resolution to return to the track of healthy and orderly.

\section{Summary}

As the most typical and main grass-roots component of our society, the countryside is an important field for the construction of the rule of law. It is necessary to integrate the problem of rural dispute settlement mechanism into the high degree of the rule of law development, to solve rural disputes in a fair and timely manner, to avoid the sharp change of contradictions and conflicts to prevent the difference between urban and rural areas in order to avoid the rule of law, which is of great significance to social stability and harmonious society construction. The rural dispute is mixed with tradition and modernity, the law and morals, the ethics, the law and the local people's covenant and so on, is the unique and extremely complicated dispute pattern of Chinese society, establishing and perfecting the rural diversification dispute settlement mechanism also must be fully grasp the rural social reality, fully consider the rule of law society construction of the whole pursuit. With progressive era, the research of diversified dispute settlement mechanism of becoming mature and more and more reasonable system architecture, the social function of increasingly significant is determined.

\section{References}

[1] Yu lina,Nie chengtao. Resolution mechanism of conflict resolution in community [M]. Beijing: China social publishing house, (2010),p.174.

[2] Fan yu et al. The construction of diversified dispute resolution mechanism and harmonious society [M]. Beijing: economic science press, (2011),p.36.

[3] Tang wei, Liu tao. Government resolution mechanism of rural disputes [J]. Law BBS, 2008(3):pp.115-117. 